\title{
Is organizational justice climate at the workplace associated with individual-level quality of care and organizational affective commitment? A multi-level, cross-sectional study on dentistry in Sweden
}

\author{
Hanne Berthelsen ${ }^{1}$ [D $\cdot$ Paul Maurice Conway ${ }^{2} \cdot$ Thomas Clausen $^{3}$
}

Received: 5 June 2017 / Accepted: 2 November 2017 / Published online: 9 November 2017

(C) The Author(s) 2017. This article is an open access publication

\begin{abstract}
Purpose The aim of this study is to investigate whether organizational justice climate at the workplace level is associated with individual staff members' perceptions of care quality and affective commitment to the workplace.

Methods The study adopts a cross-sectional multi-level design. Data were collected using an electronic survey and a response rate of $75 \%$ was obtained. Organizational justice climate and affective commitment to the workplace were measured by items from Copenhagen Psychosocial Questionnaire and quality of care by three self-developed items. Non-managerial staff working at dental clinics with at least five respondents ( $n=900$ from 68 units) was included in analyses. A set of Level-2 random intercept models were built to predict individual-level organizational affective commitment and perceived quality of care from unit-level organizational justice climate, controlling for potential confounding by group size, gender, age, and occupation.

Results The results of the empty model showed substantial between-unit variation for both affective commitment (ICC-1 $=0.17$ ) and quality of care (ICC-1 $=0.12$ ). The overall results showed that the shared perception of organizational justice climate at the clinical unit level was
\end{abstract}

Hanne Berthelsen

hanne.berthelsen@mah.se

1 Centre for Work Life and Evaluation Studies (CTA) and the Faculty of Odontology, Malmö University, Malmö, Sweden

2 Department of Psychology, Copenhagen University, Copenhagen, Denmark

3 National Research Centre for the Working Environment, Copenhagen, Denmark significantly associated with perceived quality of care and affective commitment to the organization $(p<0.001)$.

Conclusions Organizational justice climate at work unit level explained all variation in affective commitment among dental clinics and was associated with both the individual staff members' affective commitment and perceived quality of care. These findings suggest a potential for that addressing organizational justice climate may be a way to promote quality of care and enhancing affective commitment. However, longitudinal studies are needed to support causality in the examined relationships. Intervention research is also recommended to probe the effectiveness of actions increasing unit-level organizational justice climate and test their impact on quality of care and affective commitment.

Keywords Psychosocial work environment - COPSOQ · Health care · Dentistry $\cdot$ Care quality $\cdot$ Affective organizational commitment

\section{Introduction}

An important target of research into organizational functioning pertains to identifying factors that may contribute towards enhancing efficiency and quality of production processes, while simultaneously sustaining the motivation and well-being of employees (Morrison et al. 2007). In this perspective, the concept of job resources from the Job Demands-Resources model (Demerouti et al. 2001) acquires particular salience. Job resources touch upon factors in the psychosocial work environment that, on the one hand, enhance the ability of employees to fulfil their work role and achieve work-related goals, and, on the other hand, sustain motivation, well-being, and development of employees (Schaufeli and Bakker 2004). 
In many western countries, health care organizations are challenged by changing and increasing needs of the population, costly advances in treatment options, and limited financial resources. Both the European population and the health care workforce are ageing, making the recruitment of new staff a concern for the future (Harford 2009; Rechel et al. 2009; World Health Organization Europe 2015). Staff turnover, recruiting, and introducing new employees is expensive for healthcare institutions, particularly so in the case of highly skilled jobs (Blatter et al. 2012; Li and Jones 2013). These problems are also observable in the Swedish public dental sector, which is characterised by demanding working conditions and an ageing work force and, hence, by projected increases in turnover rates (Bejerot 1998; Berthelsen et al. 2017; Hjalmers 2005; Nyqvist et al. 2016; The National Board of Health and Welfare 2010).

In the present study, we focus on factors in the psychosocial work environment that may be associated with perceived quality of care and affective commitment to the organization, which may play a significant role in work motivation and in retention of staff in dental health care. Being able to deliver care of high quality in health care is important for achieving the intrinsic motivational rewards from the work with patients (Berthelsen et al. 2010; Gunnarsdóttir et al. 2009; Gunnarsdóttir and Rafferty 2006; Hasenfeld 2009) and job satisfaction (Laschinger and Fida 2015; Sasser and Sørensen 2016; Van Eenoo et al. 2016). Both high motivation and job satisfaction may, in turn, promote the retention of healthcare workers (Hayes et al. 2006). Staff's perception of providing quality care can also be regarded as an indicator of organizational performance, given its significant association with outcomes such as lower staff turnover (Castle and Engberg 2005) and positive patient outcomes (McHugh and Stimpfel 2012). Self-reported perception of care quality at hospitals predicts, for example, patient mortality, failure to rescue, patient satisfaction, and process of care measures (McHugh and Stimpfel 2012). In addition, leadership style, sufficient staffing, and the well-being of staff are related with the quality of care provided (see, e.g., Aiken et al. 2014; Bodenheimer and Sinsky 2014; Castle et al. 2007; Firth-Cozens and Mowbray 2001; Hunt et al. 2014; Laschinger and Leiter 2006; Laschinger et al. 2001, 2014; Li et al. 2013).

Another concept of particular organizational interest in relation to the challenges regarding the recruitment of manpower is affective commitment to the organization, which refers to employees' identification with and emotional attachment to their workplaces (Meyer and Allen 1997). The previous studies indicate that employees with high levels of affective commitment to their organization are more likely to provide better performances (Sharma and Dhar 2016; Stanley and Meyer 2016) and also to stay in their jobs (Clausen and Borg 2010a). Other studies demonstrate that psychosocial working conditions are associated with affective commitment to the organization (Clausen and Borg 2010b; Meyer et al. 2002). A need of extending the scope of occupational health and safety work by including holistic pro-active strategies has been emphasized, for example, by paying more attention to issues related to leadership and organizational climate (Karanika-Murray and Weyman 2013) and in particular for facing the ageing of the work force (Magnavita 2017).

In the present study, we investigate whether organizational justice climate measured at the level of work-groups is associated with (a) perceived quality of care and (b) affective commitment to the workplace measured at the individual level in the Swedish public dental sector. Organizational justice is a concept that focusses on interpersonal relations in the workplace and whether these relations are handled in a manner that employees perceive as 'fair' (Elovainio et al. 2002; Greenberg 1987). Different perspectives of organizational justice exist: Distributive justice dealing with perceived fairness in distribution of, for example, payment, and recognition or tasks; procedural justice taking up the fairness of processes (i.e., whether employees feel that decision-making procedures in the workplace are perceived as fair and transparent), and finally interactional justice, which can be further divided into interpersonal and informational justice (Colquitt et al. 2001; Elovainio et al. 2002). Repeatedly associations have been demonstrated between individual perceptions of organizational justice and various outcomes, such as, for example, organizational citizenship behaviour, performance, job satisfaction, and commitment among employees (Colquitt et al. 2001; Moorman 1991) as well as the health and well-being among employees (Elovainio et al. 2010). However, health care employees collaborate in their daily work, which makes it likely that their behaviours, attitudes, and performances are affected also by the extent to which other employees at their work unit are treated fairly. On the aggregate level, organizational justice can be understood as a climatic factor indicating the extent to which the group as a whole is treated fairly or not; however, the impact of justice at the group level is much less studied than the corresponding construct at the individual level (Naumann and Bennett 2000; Ohana 2014). One of the few studies addressing such impact showed that procedural justice climate could explain unique variance in, for example, helping behaviours at work, but not in affective commitment (Naumann and Bennett 2000). More recent research finds that organizational justice climate can be associated with affective commitment (Ohana 2014). In the context of nursing homes, results from the previous research suggest that shared perceptions of justice and trust may be of greater importance for both work ability and sick leave than individual perceptions (Kiss et al. 2014). Finally, a multi-level 
study finds a longitudinal association between organizational justice as measured at the level of work-groups and risk of depression among individual employees (Grynderup et al. 2013). Research addressing the relationship between organizational justice climate and care quality is scarce and has so far included only primary care centres (Elovainio et al. 2013; Virtanen et al. 2012). Hypothesis 1 outlines the aims of the present study:

Organizational justice measured at the workplace level is positively associated with affective commitment to the workplace and with self-assessed quality of care measured at the individual level.

To our best knowledge, no previous studies within the context of dentistry have addressed organizational justice, neither as an individual construct nor as an aggregated climate construct. The potential impact of working environment on quality of dental care is a novel field yet to be researched. In addition, affective commitment is under-researched in contrast to concepts such as work engagement and job satisfaction, which often have been addressed in research within the field of dentistry (e.g., Bergström et al. 2010; Buunk-Werkhoven et al. 2014; Denton et al. 2008; Gorter et al. 2008; Hakanen et al. 2008; Harris et al. 2009; Ordell et al. 2013; Schaufeli et al. 2002; Turner et al. 2011).

\section{Materials and methods}

\section{Study design and participants}

Data collection took place at four county councils (regions) of Sweden during the period May 2014 to January 2015. An email including a personal login and password to an online questionnaire was sent to all staff employed at the Public Dental Health Service resulting in an overall response rate of $75 \%$ (ranging from 71 to $81 \%$ among the regions) after two reminders.

For the present study, we have included non-managerial dental nurses, dental hygienists, and dentists working in general dental practice units with answers from at least five respondents. This resulted in a sample consisting of 900 respondents from 68 units (geographical separate dental practices where people conduct their daily work and share the same local management). The response rate for the chosen subsample was 73\%. Almost all respondents had a permanent position $(98.1 \%)$ and more than half $(56 \%)$ worked full time there, while only $5 \%$ worked half time or less. The characteristics of the study sample are presented in Table 1. Respondents were, on average, 2.5 years older than the non-respondents $(p \leq 0.001)$ and the response rate differed
Table 1 Distribution of baseline characteristics among participants $(n=900)$

\begin{tabular}{lrrr}
\hline & $n$ & $\%$ & Mean (SD) \\
\hline Gender & & & \\
Women & 832 & 92.4 & \\
Men & 68 & 7.6 & \\
Age (years) & & & $47.1(11.9)$ \\
Weekly total work hours & & & $36.5(6.0)$ \\
Weekly hours with patient contact & & & $30.1(9.4)$ \\
Job profile & & & \\
Dental nurses & 499 & 55.4 & \\
Dental hygienists & 196 & 21.8 & \\
Dentists & 205 & 22.8 & \\
Group size (continuous) & & & $17.3(7.4)$ \\
Group size (categories) & & & \\
5-10 respondents & 28 & 41.2 & \\
11-15 respondents & 17 & 25.0 & \\
16-20 respondents & 15 & 22.1 & \\
21-25 respondents & 4 & 5.9 & \\
26-34 respondents & 4 & 5.9 & \\
\hline
\end{tabular}

between occupational groups: dentists $64 \%$, dental hygienists $74 \%$, and dental nurses $78 \%(p \leq 0.001)$.

\section{Measures}

\section{Dependent variables}

Affective organizational commitment was measured by three items from COPSOQ II (Would you recommend a good friend to apply for a position at your workplace? Do you feel that your place of work is of great importance to you? How often do you consider looking for work elsewhere?) (Berthelsen et al. 2014b; Pejtersen et al. 2010). The items were measured by five response options (to a very small extent, to a small extent, to some extent, to a high extent, and to a very high extent), which for analytical purposes were scored 0-25-50-75-100 with 100 indicating the highest degree of commitment.

Quality of care comprises quality of technical care in relation to the interventions intended to promote the patient's health and quality of interpersonal care including relationships between patients and health professionals (Donabedian 1980). Quality of care was measured by three selfconstructed items developed for the purpose of the study: (1) Are you satisfied with the quality of the work done at your workplace? and (2) A battery of items: To what extent do you think that the following issues characterize your ward/department? (a) Is the quality of communication with patients good? and (b) Is the quality of the actual treatment 
of patients good? The first question is more global, while the item on communication represents the interpersonal care and the one on the actual treatment represent the technical aspects. The items were measured by five response options (to a very small extent, to a small extent, to some extent, to a high extent, and to a very high extent), which, for analytical purposes, were scored 0-25-50-75-100. The items were developed and tested as the first part of the Swedish validation project on COPSOQ II; details concerning the procedure have been published previously (Berthelsen et al. 2014a, b, 2016).

For both affective organizational commitment and quality of care, scaling assumptions were examined [e.g., the legitimacy of adding up items to generate scores without weighting or standardization (Likert 1932)] before the scales were established as additive indices with range $0-100$. The scale score was set to missing if respondents had answered less than two items. Cronbachs' alpha was 0.70 for affective organizational commitment and 0.81 for quality of care.

\section{Independent variables}

Organizational justice is an umbrella construct, covering distributive, procedural, and interactional justice (Cohen-Charash and Spector 2001). Organizational justice was measured by four items from COPSOQ II (Are conflicts resolved in a fair way? Are employees appreciated when they have done a good job? Are all suggestions from employees treated seriously by the management? Is the work distributed fairly?). The items were measured by five response options (to a very small extent, to a small extent, to some extent, to a high extent, and to a very high extent), which, for analytical purposes, were scored 0-25-50-75-100 with 100 indicating the highest degree of organizational justice (Berthelsen et al. 2014b; Pejtersen et al. 2010).

As for outcomes, the scale scores were calculated as the mean of the items for each scale, including only those respondents who had answered at least half of the questions included in the scale.

\section{Potential confounders}

At the unit level (level 2), we controlled for group size, while at the individual level (level 1), we controlled for the demographic variables: gender, age, and occupational group (dental nurses, dental hygienists, and dentists).

\section{Statistical analysis}

The data were analysed using multi-level linear regression analyses. We built two Level-2 random intercept models to examine the associations between group-level organizational justice and the two outcomes separately (organizational affective commitment and quality of care). We computed the intraclass correlation-2 (ICC(2)) to test if there was enough variance shared at the unit level to justify the unitlevel mean-aggregation of the individual-level organizational justice scores, using an $\operatorname{ICC}(2)$ value of $\geq 0.70$ as recommended criterion. The ICC(2) estimates the reliability of the group means and is calculated with the following formula: (Mean Square ${ }_{(\text {between) }}-$ Mean Square $\left._{(\text {within) }}\right) /$ Mean Square $_{\text {(between) }}$. The independent variables were entered according to a hierarchical procedure. First, we tested an empty model containing only the random intercept (Model 1 ), which allowed us to compute the ICC(1), i.e., the proportion of variance in the outcome attributable to between-unit effects (Level 2). As a rule of thumb, at least $5 \%$ of variance should be at Level 2 to justify the use of multi-level modelling. In Model 2, we then entered all the confounders at both the individual level (Level 1), i.e., gender, age, job profile (dental nurses, dental hygienists, dentists; the latter is the reference category), and the group level (Level 2), i.e., group size (continuous). All the individual-level confounders were grand-mean centred, as recommended (Enders and Tofighi 2007) when a Level-2 independent variable is of substantive interest and the Level-1 independent variables represent nuisance factors that need to be controlled for. In Model 3, we finally entered unit-level organizational justice as Level-2 predictor. Since we aimed to compare nested models, model fit was tested using maximum-likelihood estimation. We compared goodness-of-fit of subsequent models using the deviance statistic $-2 \log$ likelihood (-2LL) and the Akaike Information Criterion (AIC). For both indexes, lower scores indicate a better model fit, with AIC also taking model parsimony into account. All analyses were conducted using IBM SPSS for Windows, version 22.0.

\section{Results}

As shown in Table 2, all study variables were significantly correlated in the expected direction. In particular, higher unit-level organizational justice was significantly associated with higher individual-level affective commitment and quality of care.

Table 2 Mean, standard deviations (SD), and zero-order Spearman's correlations between study variables

\begin{tabular}{lrrlll}
\hline & Mean & SD & 1 & 2 & 3 \\
\hline 1 Affective commitment & 69.9 & 19.9 & - & & \\
2 Quality of care & 79.9 & 14.0 & $0.45^{* * *}$ & - & \\
$\begin{array}{l}\text { 3 Organizational justice } \\
\text { (group level) }\end{array}$ & 61.0 & 9.0 & $0.39^{* *}$ & $0.20^{* *}$ & - \\
\hline
\end{tabular}

$* * * p<0.001 ; * * p<0.01$ 
Table 3 Multi-level linear regressions testing the association of organizational justice (each 10-point increase) with affective commitment $(n=899)$ and quality of care $(n=900)$

\begin{tabular}{|c|c|c|}
\hline & $\begin{array}{l}\text { Affective commitment } \\
\text { B (SE) }\end{array}$ & $\begin{array}{l}\text { Quality of care } \\
\text { B (SE) }\end{array}$ \\
\hline \multicolumn{3}{|l|}{ Model 1 (empty) } \\
\hline Unit-level variance (SE) & $66.55(16.60)^{* * *}$ & $23.80(9.20)^{* *}$ \\
\hline $\operatorname{ICC}(1)$ & 0.17 & 0.11 \\
\hline$-2 \mathrm{LL}$ & 7853.01 & 7329.14 \\
\hline AIC & 7859.01 & 7335.14 \\
\hline \multicolumn{3}{|l|}{ Model 2} \\
\hline Gender (level 1) (ref. male) & $0.93(2.60)$ & $-0.78(1.95)$ \\
\hline Age (level 1) & $0.07(0.06)$ & $-0.01(0.04)$ \\
\hline Dental nurse (vs. dentist) (level 1) & $5.30(1.77)^{* *}$ & $4.79(1.32)^{* * *}$ \\
\hline Dental hygienist (vs. dentist) (level 1) & $4.90(1.95)^{*}$ & $3.91(1.46)^{* *}$ \\
\hline Group size (continuous) (level 2) & $0.38(0.16)^{*}$ & $0.12(0.11)$ \\
\hline Unit-level variance (SE) & $55.23(14.86)^{* * *}$ & $22.35(6.76)^{* *}$ \\
\hline $\operatorname{ICC}(1)$ & 0.14 & 0.11 \\
\hline$-2 \mathrm{LL}$ & 7829.80 & 7312.39 \\
\hline AIC & 7845.80 & 7328.39 \\
\hline \multicolumn{3}{|l|}{ Model 3} \\
\hline Gender (level 1) (ref. male) & $1.20(2.54)$ & $-0.87(1.87)$ \\
\hline Age (level 1) & $0.05(0-05)$ & $-0.04(0.04)$ \\
\hline Dental nurse (vs. dentist) (level 1) & $5.19(1.73)^{* *}$ & $5.20(1.29)^{* * *}$ \\
\hline Dental hygienist (vs. dentist) (level 1) & $4.79(1.92)^{*}$ & $4.17(1.41)^{* *}$ \\
\hline Group size (continuous) (level 2) & $0.15(0.09)$ & $0.03(0.10)$ \\
\hline Organizational justice (level 2) & $7.81(0.69)^{* * *}$ & $2.71(0.72)^{* * *}$ \\
\hline Unit-level variance (SE) & $2.11(4.53)$ & $13.93(5.57)^{*}$ \\
\hline $\operatorname{ICC}(1)$ & 0.006 & 0.07 \\
\hline$-2 \mathrm{LL}$ & 7760.43 & 7299.10 \\
\hline AIC & 7778.43 & 7317.10 \\
\hline
\end{tabular}

$* * * p<0.001 ; * * p>0.01 ; * p>0.05 . B$ unstandardized linear regression coefficient, $S E$ standard error, $I C C$ intraclass correlation coefficient, $-2 L L-2 \log$ likelihood, AIC Akaike information criterion
The ICC(2) for organizational justice was 0.76 , which indicates sufficient between-unit agreement to justify the mean-aggregation of scores at the unit level. Table 3 shows the results of the two multi-level regression analyses conducted to test the associations between grouplevel organizational justice and the two individual-level outcomes, i.e., organizational affective commitment and quality of care. The results of Model 1 (model without predictors and confounders) showed substantial between-unit variation for both affective commitment $(\operatorname{ICC}(1)=0.17)$ and quality of care $(\operatorname{ICC}(1)=0.12)$. The confounders entered in Model 2 contributed to explain significant variance in both outcomes $(p<0.001)$, resulting in improved -2LL and AIC indexes pointing to a better model fit. Specifically, both being a dental nurse and a dental hygienist versus being a dentist were related to higher affective commitment and higher quality of care. Higher group size was significantly related to higher affective commitment only. In Model 3, after adjusting for potential confounders, unit-level organizational justice explained additional variance in both outcomes, further improving-2LL and AIC indexes as compared to Model 2. Specifically, for each 10-point increase in unitlevel organizational justice, we could observe an approx. 8-point and an approx. 3-point increase in affective commitment and quality of care scores, respectively. Notably, no significant variance in affective commitment was left to be explained after introducing unit-level organizational justice in Model 3.

\section{Discussion}

The results of this study supported our expectations that higher organizational justice climate at workplaces was associated with higher levels of affective organizational 
commitment and higher self-assessed quality of care. This corroborates the previous research from primary health care, where procedural justice at the workplace was associated with different aspects of quality care (Elovainio et al. 2013; Virtanen et al. 2012). In addition, our results concerning the importance of organizational justice climate for staff members' affective commitment were in line with our expectations based on the previous research (cf Ohana 2014). According to Aalto et al. (2014), high levels of organizational justice are associated with high levels of job satisfaction. Other studies indicate that low levels of organizational justice are associated with stress-related symptoms, low psychological well-being (Elovainio et al. 2015), and risk of depression (Grynderup et al. 2013). Taken together, these findings indicate that organizational justice is a job resource that may, on the one hand, contribute to enhancing the wellbeing of employees, and, on the other hand, support quality and efficiency in the production process.

The previous research in the context of nursing has indicated a mediating effect of affective commitment on the relationship between individual perceptions of organizational justice and work performance (Sharma and Dhar 2016). This corresponds with our finding of a moderate to high bivariate correlation at the individual level between the three main variables under study, and even that the shared perception of justice climate at the workplace was more strongly associated with affective commitment than with quality of care at the individual level. Investigating whether affective commitment mediates the association between organizational justice and perceived quality of care as proposed by Sharma and Dhar (2016) will be a relevant topic for further investigation in a longitudinal design (cf. Taris and Kompier 2006).

The results of our study show that organizational justice climate explained all variation in affective commitment as well as part of the variation in quality of care between units. Affective commitment is an antecedent of actual turnover (Clausen and Borg 2010a) and was also found to reduce the risk of sickness absence (Clausen et al. 2014; Meyer et al. 2002) and poor psychological well-being (Clausen et al. 2015). In a corresponding way, quality of care is associated with a range of patient-related outcomes such as patient satisfaction and patient mortality (McHugh and Stimpfel 2012). Thereby we see a potential in future research aiming at affecting these important outcomes through improvements of organizational justice climate. Even though climatic factors may be complicated to address in interventions, a way forward seems to be through training of managers to promote organizational justice for their subordinates (Nakamura et al. 2016). Though, worth noticing is that this is just one aspect for finding solutions of a complex problem.

Health care of today-including dentistry-is widely organized as team care based on collaboration among different occupations (Kravitz et al. 2015). However, making teamwork working in practice can be challenging (Abelsen and Olsen 2008; Candell and Engstrom 2010). Working in a team is facilitated by a shared understanding of the means and the goals, but perceptions of, for example, efficiency of team care may vary considerably among the dental occupational groups (Muroga et al. 2015). The previous research has also found that dental nurses have a more positive attitude to quality assurance issues and more knowledge on these topics than dentists (Pilgård et al. 2007). On this background, it is worth noticing that the auxiliary staff on average assessed the quality of care to be better than what the dentists did. This result corroborate the previous research pointing to the importance of promoting leadership practices and an organizational climate facilitating teamwork and shared goals in the provision of health care services (Chilcutt 2009; Willcocks 2016).

In the present study, we found that organizational justice climate measured at the workplace level was associated with both individual-level organizational affective commitment and quality of care. These findings support the relevance of multi-level models in investigating complex phenomena in contemporary work organizations. Multilevel models have been used in several studies over the past decade (Bliese and Britt 2001; Clausen et al. 2015; Diez-Roux 2000; Kirwan et al. 2013; Labriola et al. 2006; Li et al. 2013; Nielsen and Daniels 2012; Roux 2004) and must be considered relevant in the study of the current work organizations, as multi-level models (a) offer more realistic analyses of organizational phenomena than analyses that focus exclusively on the individual level and (b) provide knowledge that may be more directly applicable for interventions aiming to improve the psychosocial working conditions in work-groups.

\section{Limitations and strengths}

It can be considered a weakness of the present study that it is based on a cross-sectional study where the same individual rates both the independent and dependent variables. These ratings may, indeed, be affected by variance from unobserved third variables, as, for instance, the mood of the respondent in the response situation. However, the potential risk of common method bias is decreased in a multilevel design (Clausen et al. 2015; Podsakoff et al. 2003). Another limitation may be that the sample comprised one sector only, limiting the generalizability of our findings to other professions within the health care sector. Finally, given the relatively small sample size in the present study, we decided to limit the number of potential confounders to be included in the analyses. On the other hand, we find that the use of items from a well-established questionnaire and a scale measuring quality of care developed from a series 
of personal interviews constitute strengths of our study as it adds to reliability and construct validity.

In research, organizational justice climate is typically operationalized into sub-dimensions of procedural, distributive, and relational justice (e.g., Ohana (2014). Obviously, this is important for a better understanding of underlying mechanisms. In the present study, we have chosen to operationalize organizational justice climate using a global scale shown to be valid as a group construct and often used for workplace surveys in connection to the organizational development (Berthelsen et al. 2016; Pejtersen et al. 2010). As a considerable proportion of care quality and all the shared variance in affective commitment between units were explained by this operationalization of organizational justice climate, this will facilitate knowledge transferral from research to practice. In addition, the results can be regarded as strengthening the relevance and credibility of the COPSOQ scale for organizational justice for use at an aggregated level.

\section{Conclusion}

Organizational justice climate at work unit level explained all variation in affective commitment among dental clinics and was associated with the individual staff members' affective commitment and perceived quality of care. These findings suggest a potential for addressing organizational justice climate as a way of promoting quality of care and enhancing affective commitment. However, longitudinal studies are needed to support causality in the examined relationships. Intervention research is also recommended to probe the effectiveness of actions increasing unit-level organizational justice climate and test their impact on quality of care and affective commitment.

\section{Compliance with ethical standards}

Funding This study was funded by the Swedish Research Council for Health, Working Life and Welfare (Grant 2012-00796).

Conflict of interest The authors declare that they have no conflict of interest.

Ethical approval All procedures performed were in accordance with the ethical standards of the national research committee and with the 1964 Helsinki declaration and its later amendments or comparable ethical standards. The study was approved by the Regional Ethics Board in Southern Sweden (Dnr. 2013/256 \& 2013/505).

Informed consent Informed consent was obtained from all individual participants included in the study.

Open Access This article is distributed under the terms of the Creative Commons Attribution 4.0 International License (http:// creativecommons.org/licenses/by/4.0/), which permits unrestricted use, distribution, and reproduction in any medium, provided you give appropriate credit to the original author(s) and the source, provide a link to the Creative Commons license, and indicate if changes were made.

\section{References}

Aalto A-M, Heponiemi T, Väänänen A, Bergbom B, Sinervo T, Elovainio M (2014) Is working in culturally diverse working environment associated with physicians' work-related well-being? A cross-sectional survey study among Finnish physicians. Health Policy 117:187-194

Abelsen B, Olsen JA (2008) Task division between dentists and dental hygienists in Norway. Community Dent Oral Epidemiol 36:558566. https://doi.org/10.1111/j.1600-0528.2008.00426.x

Aiken LH et al (2014) Nurse staffing and education and hospital mortality in nine European countries: a retrospective observational study. The Lancet 383:1824-1830

Bejerot E (1998) Dentistry in Sweden Healthy work or ruthless efficiency? Dissertation, Lund University, Department of Dental Public Health

Bergström K, Söderfeldt B, Berthelsen H, Hjalmers K, Ordell S (2010) Overall job satisfaction among dentists in Sweden and Denmark: a comparative study, measuring positive aspects of work. Acta Odontol Scand 68:344-353. https://doi.org/10.3109/00016357.2 010.514719

Berthelsen H, Hjalmers K, Pejtersen JH, Söderfeldt B (2010) Good Work for dentists - a qualitative analysis. Community Dent Oral Epidemiol 38:159-170. https://doi. org/10.1111/j.1600-0528.2009.00517.x

Berthelsen H, Lönnblad A, Hakanen J, Kristensen TS, Axtelius B, Bjørner JB, Westerlund H (2014a) Cognitive interviewing used in the development and validation of Copenhagen Psychosocial Questionnaire in Sweden. Conference paper presented at the Nordic Work Life Conference- Stream 26 Methodological challenges for working life and labour market studies. Gothenburg, Sweden

Berthelsen H, Westerlund H, Kristensen TS (2014b) COPSOQ II - en uppdatering och språklig validering av den svenska versionen av en enkät för kartläggning av den psykosociala arbetsmiljön på arbetsplatser. Report No.: 326. Stress Research Institute, Stockholm University

Berthelsen H, Hakanen J, Kristensen T, Lönnblad A (2016) Westerlund H (2016) A Qualitative Study on the Content Validity of the Social Capital Scales in the Copenhagen Psychosocial Questionnaire (COPSOQ II). Scand J Work Org Psychol 1:5

Berthelsen H, Westerlund H, Hakanen JJ, Kristensen TS (2017) It is not just about occupation, but also about where you work. Community Dent Oral Epidemiol. https://doi.org/10.1111/ cdoe.12300. [Epub ahead of print]

Blatter M, Muehlemann S, Schenker S (2012) The costs of hiring skilled workers. Eur Econ Rev 56:20-35

Bliese PD, Britt TW (2001) Social support, group consensus and stressor-strain relationships: social context matters. J Org Behav 22:425-436

Bodenheimer T, Sinsky C (2014) From triple to quadruple aim: care of the patient requires care of the provider. Annals of fam med 12:573-576. https://doi.org/10.1370/afm.1713

Buunk-Werkhoven YA, Hollaar VR, Jongbloed-Zoet C (2014) Work engagement among Dutch dental hygienists. J Public Health Dent 74:227-233

Candell A, Engstrom M (2010) Dental hygienists' work environment: motivating, facilitating, but also trying. Int J Dental Hygiene $8: 204-212$ 
Castle NG, Engberg J (2005) Staff turnover and quality of care in nursing homes. Med Care 43:616-626

Castle NG, Engberg J, Men A (2007) Nursing home staff turnover: impact on nursing home compare quality measures. The Gerontologist 47:650-661

Chilcutt AS (2009) Exploring leadership and team communication within the organizational environment of a dental practice. J Am Dent Ass 140:1252-1258

Clausen T, Borg V (2010a) Do positive work-related states mediate the association between psychosocial work characteristics and turnover? A longitudinal analysis. Int J Stress Manag 17:308 324. https://doi.org/10.1037/a0021069

Clausen T, Borg V (2010b) Psychosocial work characteristics as predictors of affective organisational commitment: a longitudinal multi-level analysis of occupational well-being. Applied Psychology: Health and Well-Being 2:182-203

Clausen T, Burr H, Borg V (2014) Does Affective Organizational Commitment and Experience of Meaning at Work Predict Long-Term Sickness Absence? An Analysis of Register-Based Outcomes Using Pooled Data on 61,302 Observations in Four Occupational Groups. J Occ Env Med 56:129-135

Clausen T, Christensen KB, Nielsen K (2015) Does Group-Level Commitment Predict Employee Well-Being?: a Prospective Analysis. J Occ Env Med 57:1141-1146

Cohen-Charash Y, Spector PE (2001) The role of justice in organizations: a meta-analysis. Org Beh Human Decis Processes $86: 278-321$

Colquitt JA, Conlon DE, Wesson MJ, Porter CO, Ng KY (2001) Justice at the millennium: a meta-analytic review of 25 years of organizational justice research. J Appl Psychol 86:425

Demerouti E, Bakker AB, Nachreiner F, Schaufeli WB (2001) The job demands-resources model of burnout. J Appl Psychol 86(3):499

Denton D, Newton J, Bower E (2008) Occupational burnout and work engagement: a national survey of dentists in the United Kingdom. Br Dent J 205(7):E13

Diez-Roux AV (2000) Multilevel analysis in public health research. Annu Rev Publ Health 21:171-192

Donabedian A (1980) The definition of quality: a conceptual exploration. Explorations in quality assessment and monitoring 1:3-31

Elovainio M, Kivimäki M, Vahtera J (2002) Organizational justice: evidence of a new psychosocial predictor of health. Am J Pub health 92:105-108

Elovainio M, Heponiemi T, Sinervo T, Magnavita N (2010) Organizational justice and health; review of evidence. G Ital Med Lav Ergon 32(3):B5-B9

Elovainio $\mathrm{M}$ et al (2013) Is organizational justice associated with clinical performance in the care for patients with diabetes in primary care? Evidence from the improving Quality of care in Diabetes study. Fam Pract 30(1):31-39. https://doi.org/10.1093/fampra/ cms048

Elovainio $\mathrm{M}$ et al (2015) Stressful work environment and wellbeing: what comes first? J Occ Health Psychol 20(3):289

Enders CK, Tofighi D (2007) Centering predictor variables in crosssectional multilevel models: a new look at an old issue. Psychol Methods 12(2):121

Firth-Cozens J, Mowbray D (2001) Leadership and the quality of care. Quality in Health Care 10(suppl 2):ii3-ii7

Gorter RC, Te Brake HJ, Hoogstraten J, Eijkman MA (2008) Positive engagement and job resources in dental practice. Community Dent Oral Epidemiol 36:47-54

Greenberg J (1987) A taxonomy of organizational justice theories. Acad Man Rev 12:9-22

Grynderup MB et al. (2013) Work-unit measures of organisational justice and risk of depression-a 2-year cohort study. Occup Environ Med 2012-101000
Gunnarsdottir S, Rafferty AM (2006) Enhancing working conditions. In: Dubois CA, McKee M, Nolte E (eds) Human resources for health in Europe, Open University Press, McGraw-Hill Education, UK, pp 155-172

Gunnarsdóttir S, Clarke SP, Rafferty AM, Nutbeam D (2009) Front-line management, staffing and nurse-doctor relationships as predictors of nurse and patient outcomes. A survey of Icelandic hospital nurses. Int J Nurs Stud 46:920-927

Hakanen JJ, Schaufeli WB, Ahola K (2008) The job demands-resources model: a three-year cross-lagged study of burnout, depression, commitment, and work engagement. Work Stress 22:224-241

Harford J (2009) Population ageing and dental care. Community Dent Oral Epidemiol 37:97-103

Harris R, Burnside G, Ashcroft A, Grieveson B (2009) Job satisfaction of dental practitioners before and after a change in incentives and governance: a longitudinal study. Br Dental J 207(2):E4

Hasenfeld Y (2009) Human services as complex organizations, 2nd edn. Sage Publications, Los Angeles

Hayes LJ et al (2006) Nurse turnover: a literature review. Int J Nurs Stud 43:237-263

Hjalmers K (2005) Good work for dentists-ideal and reality for female unpromoted general practice dentists in a region of Sweden. Swed Dent J Suppl 182:10-136 Dissertation, Malmö University

Hunt SR, Corazzini K, Anderson RA (2014) Top nurse-management staffing collapse and care quality in nursing homes. J Appl Gerontol 33:51-74. https://doi.org/10.1177/0733464812455096

Karanika-Murray M, Weyman AK (2013) Optimising workplace interventions for health and well-being: a commentary on the limitations of the public health perspective within the workplace health arena. Int J Workplace Health Manag 6:104-117

Kirwan M, Matthews A, Scott PA (2013) The impact of the work environment of nurses on patient safety outcomes: a multi-level modelling approach. Int J Nurs Stud 50:253-263

Kiss P, De Meester M, Kristensen TS, Braeckman L (2014) Relationships of organizational social capital with the presence of "gossip and slander," "quarrels and conflicts," sick leave, and poor work ability in nursing homes. Int Arch Occup Environ Health 87:929-936. https://doi.org/10.1007/s00420-014-0937-6

Kravitz A, Bullock A, Cowpe J, Barnes E (2015) EU manual of dental practice 2015, Edition 5.1. Cardiff University, Cardiff

Labriola M, Lund T, Christensen KB, Kristensen TS (2006) Multilevel analysis of individual and contextual factors as predictors of return to work. J Occup Environ Med 48:1181-1188

Laschinger HKS, Fida R (2015) Linking nurses' perceptions of patient care quality to job satisfaction: the role of authentic leadership and empowering professional practice environments. J Nurs Adm 45:276-283. https://doi.org/10.1097/nna.0000000000000198

Laschinger HKS, Leiter MP (2006) The impact of nursing work environments on patient safety outcomes: the mediating role of burnout engagement. J Nurs Admin 36:259-267

Laschinger HKS, Shamian J, Thomson D (2001) Impact of magnet hospital characteristics on nurses' perceptions of trust, burnout, quality of care, and work satisfaction. Nurs Econ 19(5):209

Laschinger HKS, Read E, Wilk P, Finegan J (2014) The influence of nursing unit empowerment and social capital on unit effectiveness and nurse perceptions of patient care quality. J Nurs Admin $44: 347-352$

Li Y, Jones CB (2013) A literature review of nursing turnover costs. J Nurs Manag 21:405-418

Li B et al (2013) Group-level impact of work environment dimensions on burnout experiences among nurses: a multivariate multilevel probit model. Int J Nurs Stud 50:281-291

Likert R (1932) A technique for the measurement of attitudes. Columbia University Press, New York 
Magnavita N (2017) Productive aging, work engagement and participation of older workers. A triadic approach to health and safety in the workplace. Epidemiol Biostat Pub. Health 14(Suppl 2):2. https://doi.org/10.2427/12436

McHugh MD, Stimpfel AW (2012) Nurse reported quality of care: a measure of hospital quality. Res Nurs Health 35:566-575

Meyer JP, Allen N (1997) Commitment in the workplace: theory, research, and application. Sage publications, Thousand Oaks

Meyer JP, Stanley DJ, Herscovitch L, Topolnytsky L (2002) Affective, continuance, and normative commitment to the organization: a meta-analysis of antecedents, correlates, and consequences. J Vocat Behav 61:20-52

Moorman RH (1991) Relationship between organizational justice and organizational citizenship behaviors: Do fairness perceptions influence employee citizenship? J Appl Psychol 76:845

Morrison EE, Burke GC III, Greene L (2007) Meaning in motivation: Does your organization need an inner life? J Health Hum Serv Admin 30(1):98-115

Muroga R, Tsuruta J, Morio I (2015) Disparity in perception of the working condition of dental hygienists between dentists and dental hygiene students in Japan. Int J Dent Hyg 13:213-221

Nakamura S, Somemura H, Sasaki N, Yamamoto M, Tanaka M, Tanaka $\mathrm{K}$ (2016) Effect of management training in organizational justice: a randomized controlled trial. Ind Health 54:263-271

Naumann SE, Bennett N (2000) A case for procedural justice climate: development and test of a multilevel model. Acad Manag J 43:881-889

Nielsen K, Daniels K (2012) Does shared and differentiated transformational leadership predict followers' working conditions and well-being? Leadership Quart 23:383-397

Nyqvist E, Arnrup K, Berthelsen H (2016) Belastningssymtom och sviktande arbetsförmåga: en utmaning för tandvården. Tandläkartidningen 14:54-61

Ohana M (2014) A multilevel study of the relationship between organizational justice and affective commitment: the moderating role of organizational size and tenure. Pers Rev 43:654-671

Ordell S, Söderfeldt B, Hjalmers K, Berthelsen H, Bergström K (2013) Organization and overall job satisfaction among publicly employed, salaried dentists in Sweden and Denmark. Acta Odontol Scand 71:1443-1452. https://doi.org/10.3109/00016357.201 3.767933

Pejtersen JH, Kristensen TS, Borg V, Bjorner JB (2010) The second version of the Copenhagen Psychosocial Questionnaire. Scand J Pub Health 38(3 Suppl):8-24. https://doi. org/10.1177/1403494809349858

Pilgård G, Söderfeldt B, Hjalmers K, Rosenquist J (2007) Work environment factors affecting quality work in Swedish oral and maxillofacial surgery. Swed Dent J 32:149-155

Podsakoff PM, MacKenzie SB, Lee J-Y, Podsakoff NP (2003) Common method biases in behavioral research: a critical review of the literature and recommended remedies. J Appl Psychol 88:879-903
Rechel B, Doyle Y, Grundy E, McKee M (2009) How can health systems respond to population ageing? European Observatory on Health Systems and Policies, Policy Brief 10

Roux AVD (2004) The study of group-level factors in epidemiology: rethinking variables, study designs, and analytical approaches. Epidemiol Rev 26:104-111

Sasser M, Sørensen OH (2016) Doing a good job-the effect of primary task quality on well-being and job satisfaction. Hum Factors Man 26:323-336. https://doi.org/10.1002/hfm.20648

Schaufeli WB, Bakker AB (2004) Job demands, job resources, and their relationship with burnout and engagement: a multi-sample study. J Org Behav 25:293-315

Schaufeli WB, Salanova M, González-Romá V, Bakker AB (2002) The measurement of engagement and burnout: a two sample confirmatory factor analytic approach. J Happiness Stud 3(1):71-92

Sharma J, Dhar RL (2016) Factors influencing job performance of nursing staff: mediating role of affective commitment. Pers Rev 45:161-182

Stanley DJ, Meyer JP (2016) Employee commitment and performance. In: Meyer JP (ed) Handbook of employee commitment. Edward Elgar Publishing, Cheltenham, pp 208-222

Taris TW, Kompier MA (2006) Games researchers play-Extremegroups analysis and mediation analysis in longitudinal occupational health research. Scand J Work Environ Health 32(6):463-472

The National Board of Health and Welfare (2010) Yearly planning report 2010. An analysis of the labour market for midwives, nurses, doctors, and dentists. [In Swedish: Årsrapport NPS 2010. En analys av barnmorskors, sjuksköterskors, läkares, tandhygienisters och tandläkares arbetsmarknad]

Turner S, Ross MK, Ibbetson RJ (2011) Job satisfaction among dually qualified dental hygienist-therapists in UK primary care: a structural model. Br Dent J 210(4):E5. https://doi.org/10.1038/ sj.bdj. 2011.50

Van Eenoo L, van der Roest H, van Hout H, Declercq A (2016) Quality of care and job satisfaction in the European Home Care Setting: research protocol. Int J Int Care. https://doi.org/10.5334/ijic.2519

Virtanen M et al (2012) Organizational justice in primary-care health centers and glycemic control in patients with type 2 diabetes. Med Care 50:831-835. https://doi.org/10.1097/ MLR.0b013e31825dd741

Willcocks SG (2016) Exploring leadership in the context of dentistry in the UK. Leadership Health Serv (Bradford, England) 29(2):201216. https://doi.org/10.1108/lhs-02-2016-0009

World Health Organization Europe (2015) Core health indicators in the WHO European Region Special focus: human resources for health. WHO Europe, Copenhagen 